Published in:

Gamito, S. 2006. Benthic ecology of semi-natural coastal lagoons, in the Ria Formosa

(Southern Portugal), exposed to different water renewal regimes. Hydrobiologia, 555:75-87.

H. Queiroga, M.R. Cunha, A. Cunha, M.H. Moreira, V. Quintino, A.M. Rodrigues, J. Serôdio \& R.M.

Warwick (eds), Marine Biodiversity: Patterns and Processes, Assessment, Threats, Management

and Conservation DOI 10.1007/s10750-005-1107-3

\title{
Benthic ecology of semi-natural coastal lagoons, in the Ria Formosa (Southern Portugal), exposed to different water renewal regimes
}

\section{Sofia Gamito}

IMAR, Faculdade de Ciências do Mar e do Ambiente, Universidade do Algarve, Campus de Gambelas, 8005-139,

Faro, Portugal (E-mail: sgamito@ualg.pt)

Key words: lagoon ecology, benthic macrofauna, water renewal, environmental stress, taxonomic resolution

\begin{abstract}
Several studies in semi-natural coastal lagoons in the Ria Formosa lagoonal system have been carried out. These man-made water reservoirs behave as small lagoons with one opening to the tidal channels, which may be intermittent. Because of their size, these reservoirs are ideal sites for ecological studies. Water quality and macrobenthic fauna were analysed in five water reservoirs. All reservoirs received the same incoming water through a tidal channel, but they differed in water renewal regime. Multidimensional Scaling (MDS) and Discriminant Analysis were used to evaluate the similarity among sites, stations and sampling occasions. Different levels of taxonomic resolution (family, large taxonomic groups and phylum level) were also evaluated. The separation of sites and stations became unclear using high taxonomic levels. Results from the multivariate analyses suggest a slight differentiation of the stations according to sampling occasion but a clear differentiation of the several water reservoirs. Some of the lagoons studied with low water renewal rates showed strong environmental variations. They were characterised by low diversity indexes and abundance of small-sized organisms. Other lagoons, with high water renewal rates, showed low environmental variation and well diversified and structured benthic communities. The main environmental factor that seems to affect the benthic communities was the variation in salinity between neap and spring tides, which is related with the water renewal regime. Coastal lagoons offer a protected shallow habitat, which can be highly productive. Well structured communities, controlled by k-strategists, can develop and settle in leaky lagoons, that is, lagoons with wide entrance channels and tidal currents which guarantee a good water renewal. In these lagoons, biomass can accumulate in large organisms. In contrast, lagoons with a single narrow entrance, that may be closed for long periods, are characterised by persistent physical stress and are dominated by communities of small-sized r-strategists.
\end{abstract}




\section{Introduction}

Coastal lagoons are often highly productive but, at the same time, they can be highly stressed by anthropogenic inputs and human activities (Kjerfve, 1994). Depending on their hydrology these shallow coastal environments may be characterised by gradual or sharp daily and seasonal variations in physical-chemical water parameters.

Assessing patterns in the structure of benthic communities has several advantages over experimental methods for the detection of anthropogenic disturbance (Warwick et al., 1990) or ecological conditions. Because of the sessile nature of most benthic organisms, these can integrate environmental conditions over time better than pelagic fauna. However, identification of benthic fauna to the species level are time consuming and analysis of benthic data at lower levels of taxonomic resolution has been proven to be an efficient method for detecting environmental change in strong environmental gradients (Warwick, 1988; Olsgard et al., 1998; Rumohr \& Karakassis, 1999).

The Ria Formosa lagoonal system lies along the southern coast of Portugal, extending for about $55 \mathrm{~km}$. It is a true barrier island system, comprising mainland, backbarrier lagoons, inlet deltas, barrier islands, barriers platforms and shoreface (Pilkey et al., 1989). Tidal amplitude varies from a maximum of $3.5 \mathrm{~m}$ at spring tide to 0.5 at neap tide, which causes an important semi-diurnal and fortnightly tidal amplitude fluctuation of the water volume inside the system (Falcão \& Vale, 1990). The total area covered by water during spring tides varies between 14.1 and $63.1 \mathrm{~km} 2$ and during each tidal cycle there is an exchange of almost all the water mass (Águas, 1986). There is no significant freshwater input to the system and salinity remains around 36 psu throughout the year, except during sporadic, short run-off periods (Falcão \& Vale, 1990).

The Ria Formosa lagoonal system covers a total area of $163 \mathrm{~km} 2$, of which $20 \mathrm{~km} 2$ are occupied by salinas and aquaculture ponds (CCRA, 1984). The main water reservoirs of the salinas and the extensive aquaculture ponds behave like small lagoons where there are one or more openings to a tidal channel. The water comes into the reservoir through a tidal gate, which can be manual or automatic, and is transferred to other water reservoirs by gravity or pumping, according to the salt or fish production needs. In these reservoirs, the main factors that can influence the community are the quality of the water that comes in, the reservoir size and depth and the water renewal rate. When the renewal rate is low the quality of the water inside the reservoirs may decrease. Small sizes and shallow depths can also contribute to a decrease in water quality.

These reservoirs are ideal sites for ecological studies because of their small size. Four water reservoirs were studied during 2 years, and a fifth one some years later, with the aim of analysing the macrofauna and their relation to water quality and water renewal regimes. All reservoirs received the same incoming water through a tidal channel, but they differed in water renewal regime. Therefore, we expected that the physical and chemical characteristics of the water, and 
consequently the macrofauna communities would differ due to this main environmental factor.

In previous analyses of data of the first four reservoirs data (Gamito, 1989, 1997) a separation of the sites according to water renewal rate was evident. One of the sites (Site B) had similar characteristics to the shallow-water or coastal marine systems, whereas another site (Site A) had characteristics of an environment under great stress, due to restricted water renewal. The other two sites, C and D, showed intermediate stress characteristics, but were subjected to dystrophic crisis accompanied by degradation in the water quality. These data can serve as a basis for comparing other reservoirs from the Ria Formosa lagoonal system.

The fifth reservoir (site E), studied some years later, is located between reservoirs $C$ and $D$. Due to the fact that the water is renewed every day, it is expected to be similar to site $B$ in terms of ecological characteristics. A variety of multivariate analysis techniques were used to evaluate the similarity among sites, stations and also sampling occasions. Different levels of taxonomic resolution (family, large taxonomic groups and phylum level) were also evaluated.

\section{Methods}

A 2-year sampling programme was carried out at four sites subjected to different water renewal regimes, in 1985 and 1986, with the aim of determining their current ecological conditions and relating them to the dynamics of water circulation. Some years later, in 1996/1997, a fifth water reservoir, from an aquaculture facility, was also studied. All sites, situated near Olhão, on the Ria Formosa, received the same incoming water through the Marim Channel, but they differed in water renewal regime (Fig. 1 and Table 1). At site A, a water reservoir of an inactive salina, the water was only renewed fortnightly, during the spring tides. At site $B$, a tidal-mill water reservoir, the water was partially renewed every day. Similarly, at site E, a fish farm water reservoir, the water is pumped daily to the fish production reservoirs. At two other sites (sites $C$ and $D$ ) the water was renewed according to salt production requirements, but more intensively during spring tides.

Ten sampling stations were selected at the first four sites (A, B, C and D), and another two at the fifth (site E) (Fig. 1). Two water samples were taken every month at each station, one during the neap tides, when the water renewal is minimal, and the other a week later, during the spring tides. In site $E$ water samples were taken from a site situated between the two stations. The following variables were determined: water temperature, salinity, dissolved oxygen, biochemical oxygen demand (BOD5), chlorophyll a and phaeopigments. In the first four sites determination of nutrient concentration was also carried out (nitrates, nitrites, silicates and phosphates).

Two core samples (12 cm internal diameter) were taken every 2 months in each station to determine the composition of the benthic macrofauna ( $1 \mathrm{~mm}$ mesh sieve), except in site $\mathrm{E}$, where four cores per station were taken every month (for details on sampling periodicity and variable determination see Gamito (1994, 1997) Gamito et al. (2003). 


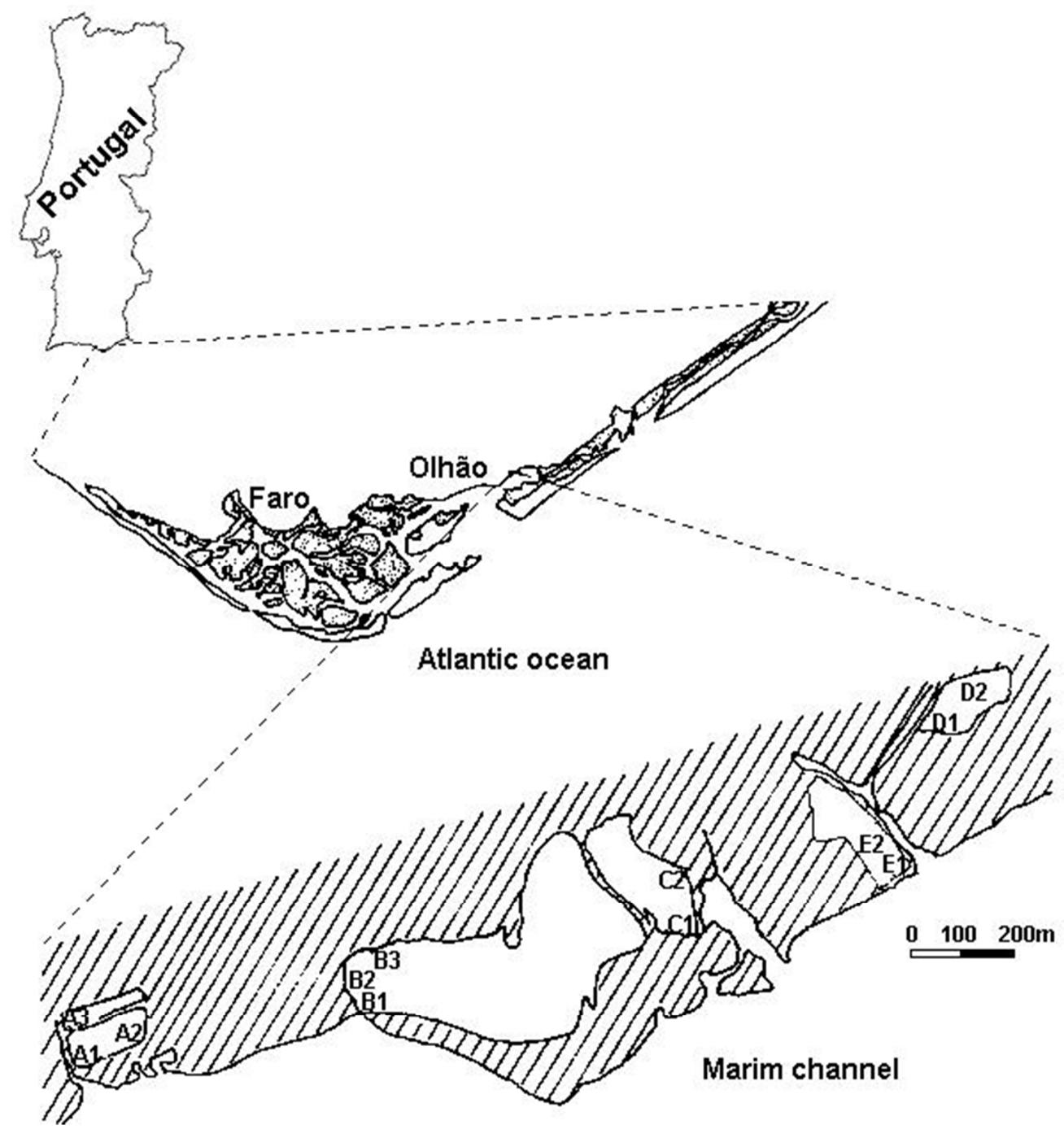

Figure 1. The study area and location of the sampling stations. Stations A1, B1, C1 and D1 are near the tidal gates. The water reservoir of site $\mathrm{E}$ had two tidal gates, one near station E1 and the other at some distance from station E2.

Table 1. Characteristics of the water reservoirs and number of stations in each site.

\begin{tabular}{llccccc}
\hline Sites & Tide gate & Water renewal & $\begin{array}{c}\text { Total } \\
\text { area } \\
(\mathrm{ha})\end{array}$ & $\begin{array}{c}\text { Mean } \\
\text { depth } \\
(\mathrm{m})\end{array}$ & $\begin{array}{c}\text { Number } \\
\text { of } \\
\text { Stations }\end{array}$ & $\begin{array}{c}\text { Vegetation } \\
\text { cover }\end{array}$ \\
\hline A - Old salinas & Manual & Every 14 days & 1.5 & $1 / 0.4$ & 3 & $<10$ \\
B - Tidal mill & Automatic & Every day & 9 & $1 / 0.6$ & 3 & 100 \\
C-Working salinas & Manual & Spring tides & 2 & $1 / 0.6$ & 2 & 50 \\
D-Working salinas & Automatic & Spring tides & 1 & $1 / 0.8$ & 2 & 100 \\
E- Aquaculture & Manual & Every day & 1.4 & $0.8 / 2.0$ & 2 & $<10$
\end{tabular}

The deeper stations were near the gates (stations A1, B1, C1 and D1), except in site E, where it was in the middle of the water reservoir (station E2). 
Total number of species, density, biomass, Shannon-Wiener diversity index and evenness (based on density data) in each site were analysed. Since the total number of species was very high and also because not all taxa could be identified to the species level, the data of all stations was grouped by families and explored with ordination techniques.

The differentiation of stations and sites at different taxonomic levels of organisation was evaluated with Multidimensional scaling (MDS) plots (Bray-Curtis dissimilarity index, root-root transformation or no transformation). The families were organised according to their phyla or to major groups within each phylum. When sorting out the animals after sediment sampling, these are usually placed in large taxonomic groups such as bivalves, gastropods, polychaetes, oligochaetes, amphipods, isopods, and so on, before the identification procedure.

MDS was also carried out on a reduced data set of the most abundant families in each station and sampling occasion. A mean density higher than 30 individuals $\mathrm{m}$ )2, considering all the stations and sampling occasions was the criteria used to select the most abundant families. The main reason for this reduced data set is that the interpretation of ordination diagrams is clear with reduced data sets than with tens or even hundreds of taxa.

With this reduced data matrix, the similarities among sites, stations and sampling occasions were then investigated with ANOSIM and Discriminant analysis. The softwares used were PRIMER (v.5.2) and Brodgar (v. 2.1). A ANOSIM two-way crossed analysis was performed, with sampling station as factor 1 and sampling month as factor 2 .

The analysis was repeated with sites as factor 1 (Null hypotheses: no site or station effect; no time effect). Only data from the first 2 years were used because the sampling periodicity at site $E$ was different (every month, during 1 year, compared with every 2 months during 2 years, at sites AD (10 stations - 6 sampling occasions with two replicates). A ANOSIM one-way analysis was performed for sites (null hypothesis: no difference among sites) and for stations (null hypothesis: no difference among stations).

In order to see how the macrofauna families were associated with the environmental variables, canonical correspondence analysis (CCA) was applied to the data (mean annual densities of the most abundant families, in each station) using the CANOCO programme (v. 4.0). The family data were root-root transformed prior to the analysis. Station E2 was not considered in this analysis, because its depth was much greater than that of all other stations of the other sites and also because water analysis was performed at only one station in this water reservoir. The BioENV routine from PRIMER software was used to select the more important environmental variables by comparing two triangular matrices, the Bray-Curtis dissimilarity matrix on root-root transformed data and a Euclidean distance matrix of the standardized environmental data (the same data matrices as used for CCA analysis). 


\section{Results}

Salinity varied greatly in site $A$, as well as in in site $C$ during the second year. This was due to reduced water renewal and high evaporation rates during summer months and rainfall during winter. Dissolved oxygen was always relatively high, which can be explained by the time of sampling (between 9 and 12 a.m.). The occasional occurrence of high BOD values indicates some instability of the ecosystem (Table 2).

While sites $B$ and $E$ were characterised by higher faunal diversity, the biomass in site $B$ was more than 5 times higher than in site $\mathrm{E}$, mainly due to the presence of large specimens of molluscs and polychaete species (Table 3 and Fig. 2). Site A had the lowest diversity but a high density of small body sized organisms, with r-strategists characteristics.

A total of 96 families were identified in the five lagoons. 27 families had a mean density higher than 30 individuals $\mathrm{m}^{-2}$, considering all the stations and sampling occasions, and represent $95.6 \%$ of all the data.

When the 96 families or the 27 most abundant families are considered, four distinct groups can be observed (Fig. 3), formed by the stations of sites A, B, D and E, regardless of the sampling date. Site $\mathrm{C}$ stations were projected in between the samples of sites $\mathrm{A}$ and $\mathrm{D}$.

The families belonged to nine phyla (Annelida; Arthropoda; Coelenterata; Echinodermata; Mollusca; Nemertini; Phoronida, Sipuncula and Chordata). Within some of these phyla other large taxonomic groups were also considered: Olygochaeta and Polychaeta in the Annelida phylum; Amphipoda, Cirripedia, Cumacea, Decapoda, Isopoda, Insecta, Leptostraca and Tanaidacea in the Arthropoda phylum; Bivalvia, Gastropoda and Polyplacophora in the Mollusca phylum. Inspection of MDS plots resulting from these two data matrices indicates that the separation of the stations and sites are not clear (Fig. 3). Stations from sites B and E are mixed as well as with some stations from sites $A, C$ and $D$. The differentiation of stations was even less evident for the analysis when no transformation of the data was previously performed.

Two-way crossed ANOSIM clearly separates sampling stations (Global $R=0.713$, significance $=0.1 \%$ ) but not the sampling occasion (Global $R=0.048$, significance $=76.7 \%$ ). The same analysis for sites and sampling occasion also separates sites (Global $R=0.808$; significance $=0.1 \%$ ) but not the sampling occasion (Global $R=0.031$; significance $=17.7 \%$ ). One-way ANOSIM confirms the separation of sites and stations (Global $R=0.843$ and $R=0.809$, respectively; significance $=0.1 \%$ ), although the stations within each site show some similarities (Pairwise comparisons: barely separable at all $(R<0.25)$ : $A 1, A 2, A 3$ and $E 1$, E2; overlapping $(R<0.50)$ : $B 1$, B2; B2, B3 and C2, D2). From the three ANOSIM tests we accept the null hypothesis in the first test: there are no differences among sampling occasions but we accept the alternative hypothesis of the two other tests: there are differences within sites and within stations. 
Table 2. Mean, maximal and minimal values of water temperature (Temp, $\left.{ }^{\circ} \mathrm{C}\right)$, salinity (Sal, p.s.u.), dissolved oxygen (DO, $\left.\mathrm{mg} \mathrm{l}^{-1}\right)$, biochemical oxygen demand (BOD, $\mathrm{mg} \mathrm{l}^{-1}$ ), chlorophyll a (Chlo, $\mathrm{mg} \mathrm{m}^{-3}$ ) and phaeopigments (Phae, $\mathrm{mg} \mathrm{m}^{-3}$ ) in each site and year.




Table 3. Mean, maximal and minimal values of number of species $(\mathrm{S})$, density $\left(\mathrm{N}\right.$, number of individuals $\left.\mathrm{m}^{-2}\right)$, biomass $\left(B\right.$, ash free dry weight $\mathrm{g} \mathrm{m}^{-2}$ ), production $\left(P\right.$, ash free dry weight $\left.\mathrm{g} \mathrm{m}^{-2} \mathrm{y}^{-1}\right)$, Shannon-Wiener diversity index ( $\mathrm{H}^{\prime}$, bits) and evenness, in each site.

\begin{tabular}{|c|c|c|c|c|c|c|c|}
\hline \multirow[t]{2}{*}{ Site } & & $S$ & $\mathrm{~N}$ & $B$ & $P$ & $\mathrm{H}$ & $\mathrm{J}$ \\
\hline & Min & 6 & 6322 & 2.9 & & 0.6 & 0.22 \\
\hline \multirow[t]{3}{*}{ A } & Mean & 9 & 11400 & 9.5 & 28.5 & 1.8 & 0.58 \\
\hline & Max & 12 & 21148 & 15.9 & & 2.9 & 0.80 \\
\hline & Min & 31 & 4848 & 18.9 & & 3.5 & 0.66 \\
\hline \multirow[t]{3}{*}{ B } & Mean & 39 & 8967 & 45.3 & 67.5 & 3.7 & 0.71 \\
\hline & Max & 47 & 12364 & 70.0 & & 4.1 & 0.78 \\
\hline & Min & 10 & 2365 & 6.1 & & 2.1 & 0.56 \\
\hline \multirow[t]{3}{*}{ C } & Mean & 16 & 5624 & 22.7 & 27.2 & 2.8 & 0.71 \\
\hline & Max & 27 & 8511 & 53.2 & & 3.5 & 0.81 \\
\hline & Min & 17 & 2962 & 22.8 & & 2.9 & 0.67 \\
\hline \multirow[t]{3}{*}{ D } & Mean & 21 & 6213 & 44.4 & 49.0 & 3.4 & 0.77 \\
\hline & Max & 24 & 10279 & 79.0 & & 3.6 & 0.82 \\
\hline & Min & 31 & 3133 & 1.8 & & 3.2 & 0.58 \\
\hline \multirow[t]{2}{*}{$E$} & Mean & 48 & 8798 & 7.4 & 22.3 & 4.0 & 0.72 \\
\hline & Max & 63 & 12630 & 11.8 & & 4.4 & 0.78 \\
\hline
\end{tabular}

The discriminant analysis reveals the great similarity among the samples taken along the different months in each station and also the similarity among the stations of each site. There is a clear separation of sites $A, B$ and $E$, with some overlapping of the stations of sites $C$ and $D$, which were projected in an intermediate position (Fig. 4). Both axes are important in the discrimination of the groups, as is indicated by the eigenvalues (Axis 1: 20.9 or $42.9 \%$ and Axis $2: 14.8$ or $30.4 \%$ ).

Both the ANOSIM and Discriminant analyses suggest a small differentiation of the stations according to sampling occasion. Consequently, the CCA was carried out with the data organised as average densities of the most abundant families per year, in each station. 

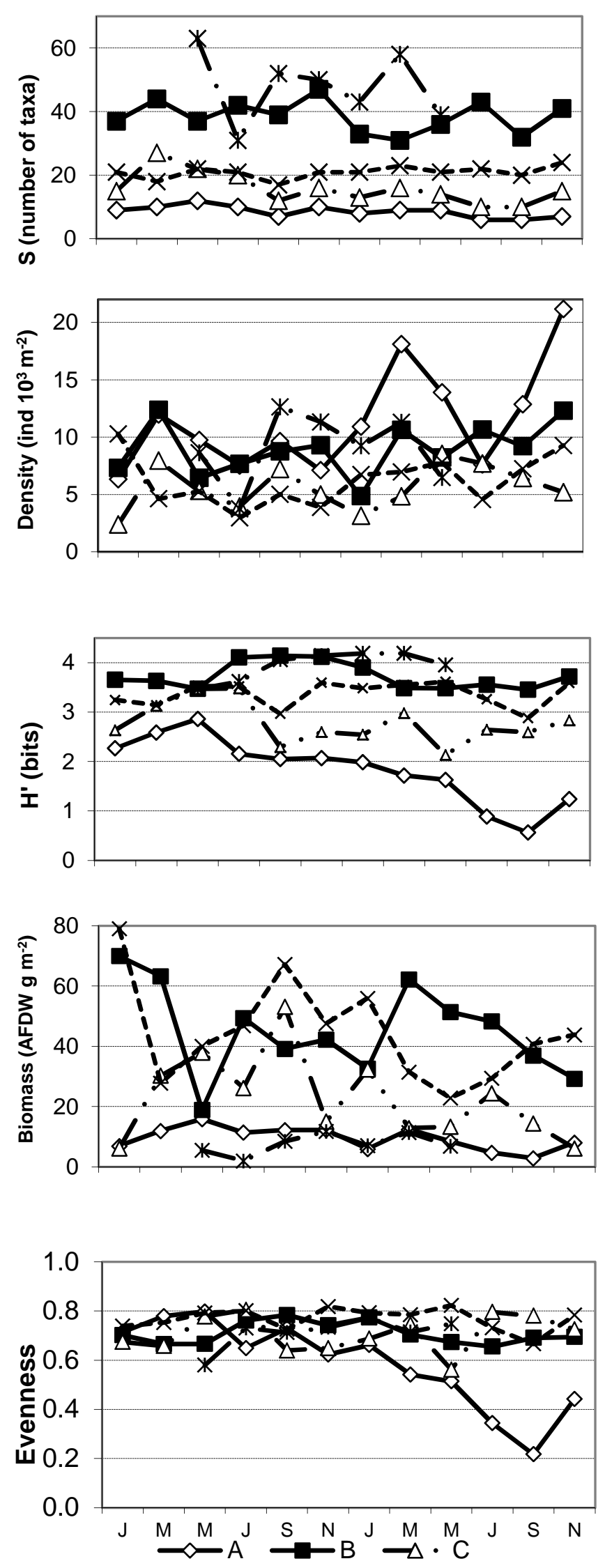

Figure 2. Variation of number of taxa, density, Shannon-Wiener diversity index, evenness and biomass per sampling occasion, in each site. 


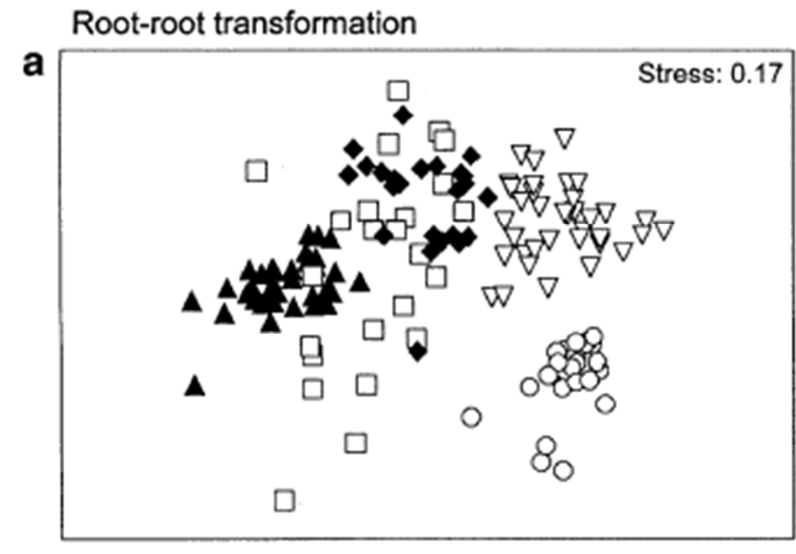

No transformation
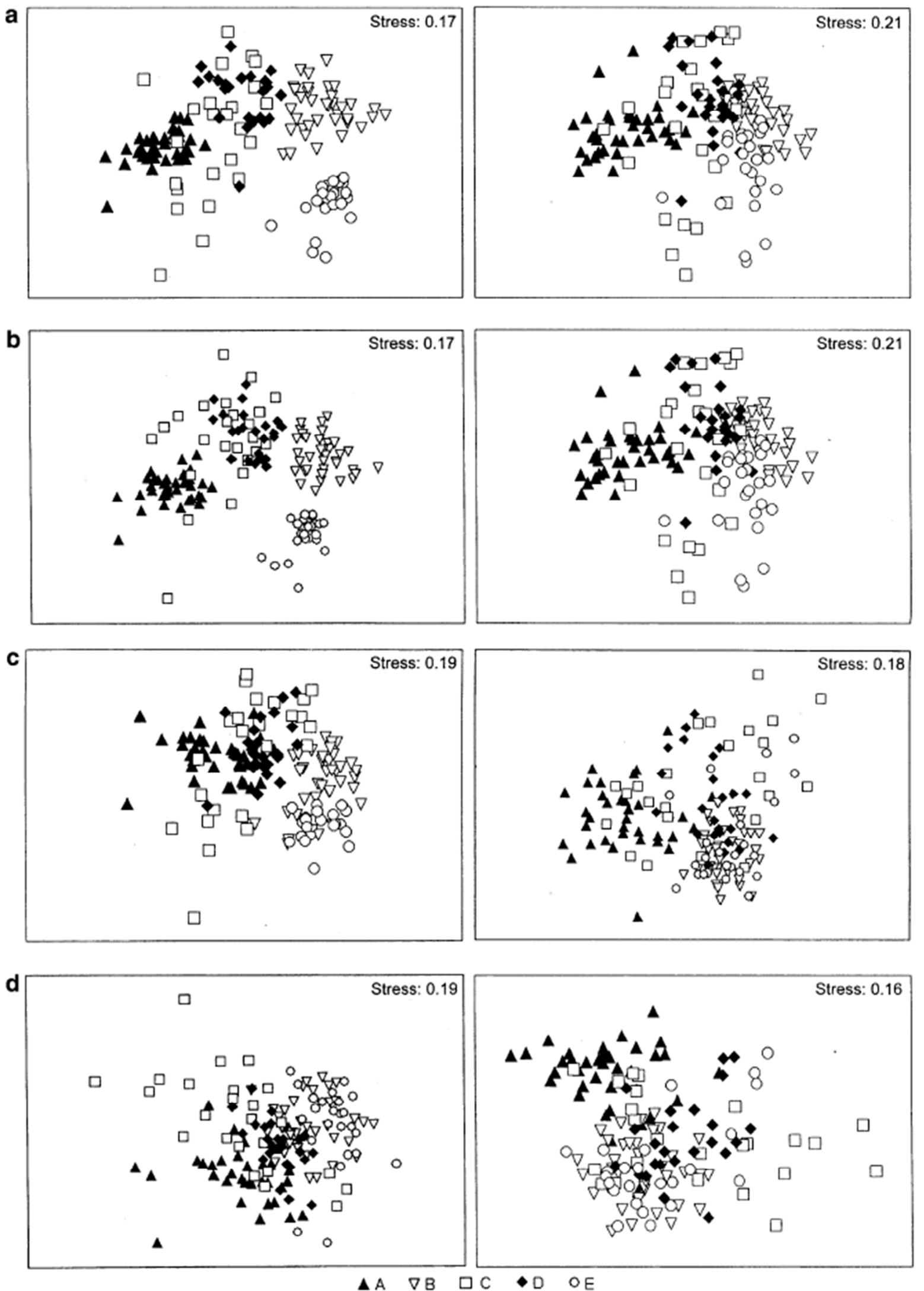

Figure 3. Multidimensional Scaling carried out with different data sets: a) 96 families; b) 27 most abundant families; c) 19 high taxonomic groups (see text for details) or d) nine Phyla; Bray-Curtis dissimilarity index, root-root transformation, or no transformation, 144 samples (12 stations, 12 sampling occasions in each station). 


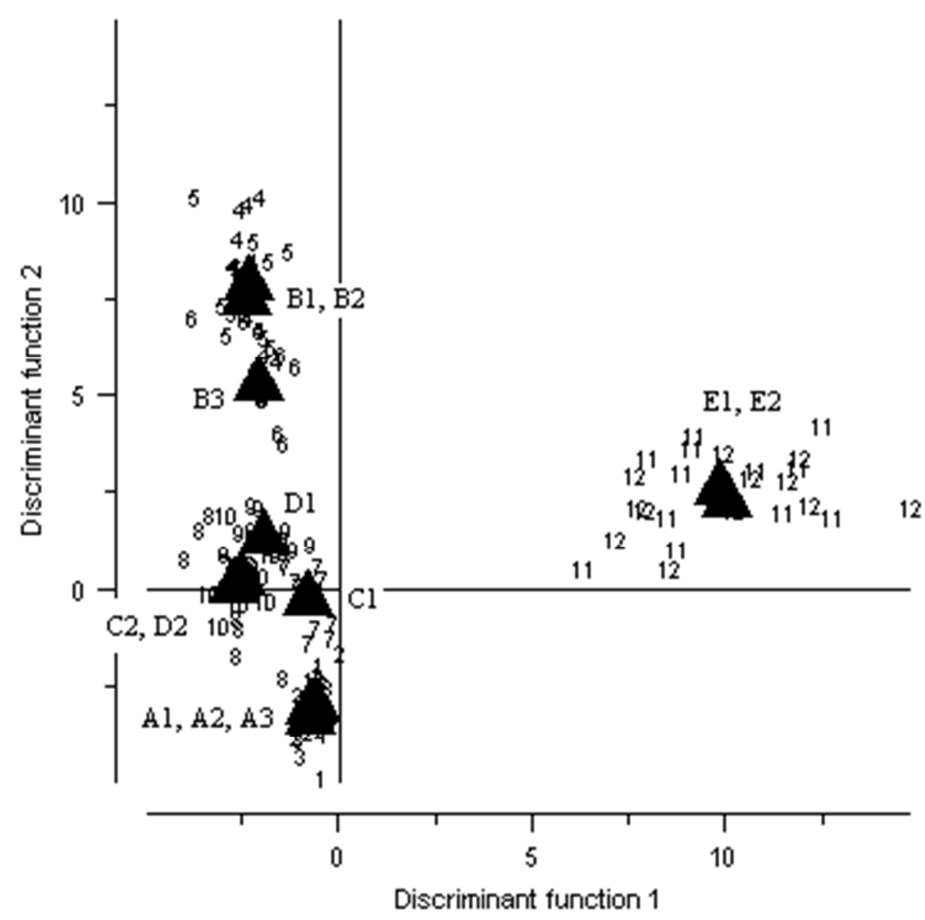

Figure 4. Discriminant analysis carried out with the same data set used in MDS. Stations codes (repeated numbers: sampling occasions in each station): $A 1-1 ; A 2-2 ; A 3-3 ; B 1-4 ; B 2-5$; B3 -6 ; $\mathrm{C} 1-7$; $\mathrm{C} 2-8$; D1 - 9; D2 - 10; E1 -11; E2 - 12. Percentage variance accounted for by the two axes: $73.3 \%$ (Axis 1: $42.9 \%$; Axis 2: $30.4 \%$ ).

The distribution of the stations on the first two axes of CCA (Fig. 5) clearly indicates a separation of stations of site $A$ and of site $C$ (second year) from the stations of the other sites, along axis one, which is correlated with high maximum-minimum salinity values. The most abundant families were Cardiidae (the bivalve Cerastoderma glaucum (Poiret, 1789)); Chironomidae (the insect larvae Chironomus salinarius Kieffer, 1915) and Hydrobiidae (Hydrobia spp.). Higher values of temperature and dissolved oxygen were also observed in these stations. Depth, phaeopigment and chlorophyll a concentrations were higher in the negative section of axis one, where stations from the other sites were projected. Higher BOD values were observed in the stations projected in the positive part of axis two.

Station E1 was separated from all the other stations, with high densities of the families Caprellidae (the amphipods Caprella acanthifera Leach,1814), Dorveilleidae (the polychaete Schistomeringos rudolphi (Delle Chiaje, 1828)) and Paraonidae (the polychaetes Aricidea cerrutii Laubier, 1967 and Paradoneis armata Glemarec, 1966).Families Ampeliscidae (the amphipods Ampelisca spp.), Aoridae (the amphipods Lembos websteri Bate, 1857 and Microdeutopus spp.), Capitellidae (the polychaetes Capitella capitata (Fabricius,1780), Heteromastus filiformis (Claparede, 1864) and Notomastus latericeus M.Sars, 1851), Gammaridae (the amphipods Gammarus spp.) and Semelidae (the bivalve Abra ovata (Philippi, 1836) were projected near the origin of the axis, being present in almost all stations. 

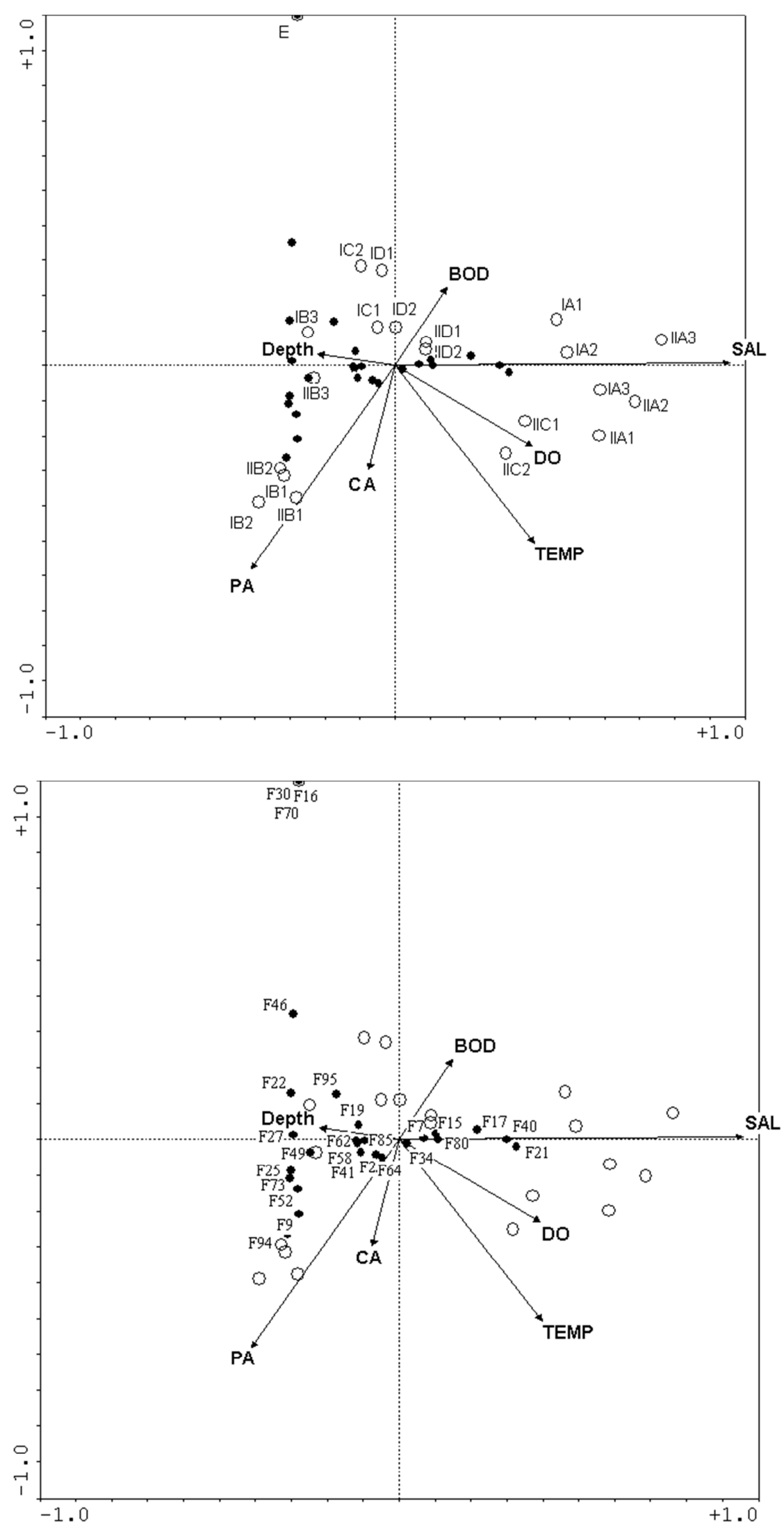

Figure 5. Canonical correspondence analysis carried out with the 27 most abundant families (mean annual values per station). Percentage variance accounted for by axes: 
Species: $I=40.2 \%$; I+II = $58.5 \%$; species-environment relation: $I=\%$; I+II=81.0\%. Monte Carlo test $P=0.005$ (the relation between taxa and environmental variables is highly significant).

Stations codes: the first character indicates the year of survey (I): 1985; (II): 1986; and subsequent ones the site and station. Environmental data: TEMP (water temperature; mean annual values in each station); SAL (salinity: difference between maximal and minimal value observed in each year, in each station); DO (dissolved oxygen: difference between maximal and minimal value observed in each year, in each station); BOD (biochemical oxygen demand; mean annual values in each station); CA and PA (chlorophyll a and phaeopigments; mean annual values in each station). Families codes:

$\begin{array}{llllllll}\text { F2 } & \text { Ampeliscidae } & \text { F21 } & \text { Chironomidae } & \text { F41 } & \text { Idoteidae } & \text { F70 } & \text { Paraonidae } \\ \text { F7 } & \text { Aoridae } & \text { F22 } & \text { Cirratulidae } & \text { F46 } & \text { Leptocheliidae } & \text { F73 } & \text { Phoronidae } \\ \text { F9 } & \text { Apseudinae } & \text { F25 } & \text { Corophiidae } & \text { F49 } & \text { Lucinidae } & \text { F80 } & \text { Semelidae } \\ \text { F15 } & \text { Capitellidae } & \text { F27 } & \text { Cumacea } & \text { F52 } & \text { Maldanidae } & \text { F85 } & \text { Spionidae } \\ \text { F16 } & \text { Caprellidae } & \text { F30 } & \text { Dorvilleidae } & \text { F58 } & \text { Nassariidae } & \text { F94 } & \text { Turritellidae } \\ \text { F17 } & \text { Cardiidae } & \text { F34 } & \text { Gammaridae } & \text { F62 } & \text { Nereididae } & \text { F95 } & \text { Veneridae } \\ \text { F19 } & \text { Cerithiidae } & \text { F40 } & \text { Hydrobiidae } & \text { F64 } & \text { Oligochaeta } & & \end{array}$

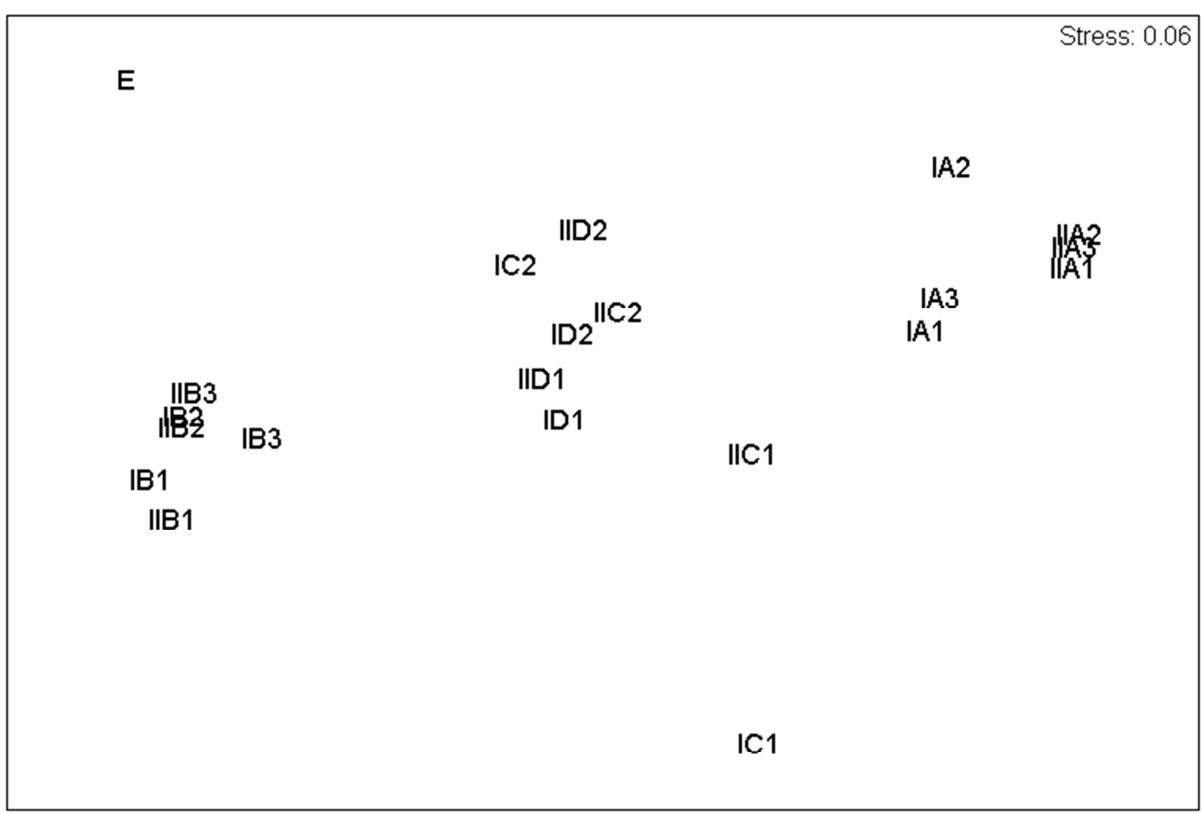

Figure 6. Multidimensional Scaling carried out with the 27 most abundant families (mean annual values per station). Stations codes as in figure 5.

The distribution of the stations on the MDS plot (Fig. 6) is comparable to the distribution of the stations in the CCA diagram (Fig. 5a). In the MDS plot there is a clear separation of stations of site $A$ and station $C 1$ from the stations of site $B$, with the stations from the other sites in between. The Bio-Env routine indicated that only the difference between the maximal and minimal salinity values observed in each year and the mean annual values of temperature were required to capture the stations pattern from the families assemblages seen in the MDS plot (matching correlation 0.698). In fact, PCA ordination performed with only these two variables resembles the MDS plot based on the 27 most abundant families (mean annual values) (Fig. 7). Salinity, phaeopigments and 
temperature, with longer arrows, were the main environmental factors singled out by CANOCO analysis.

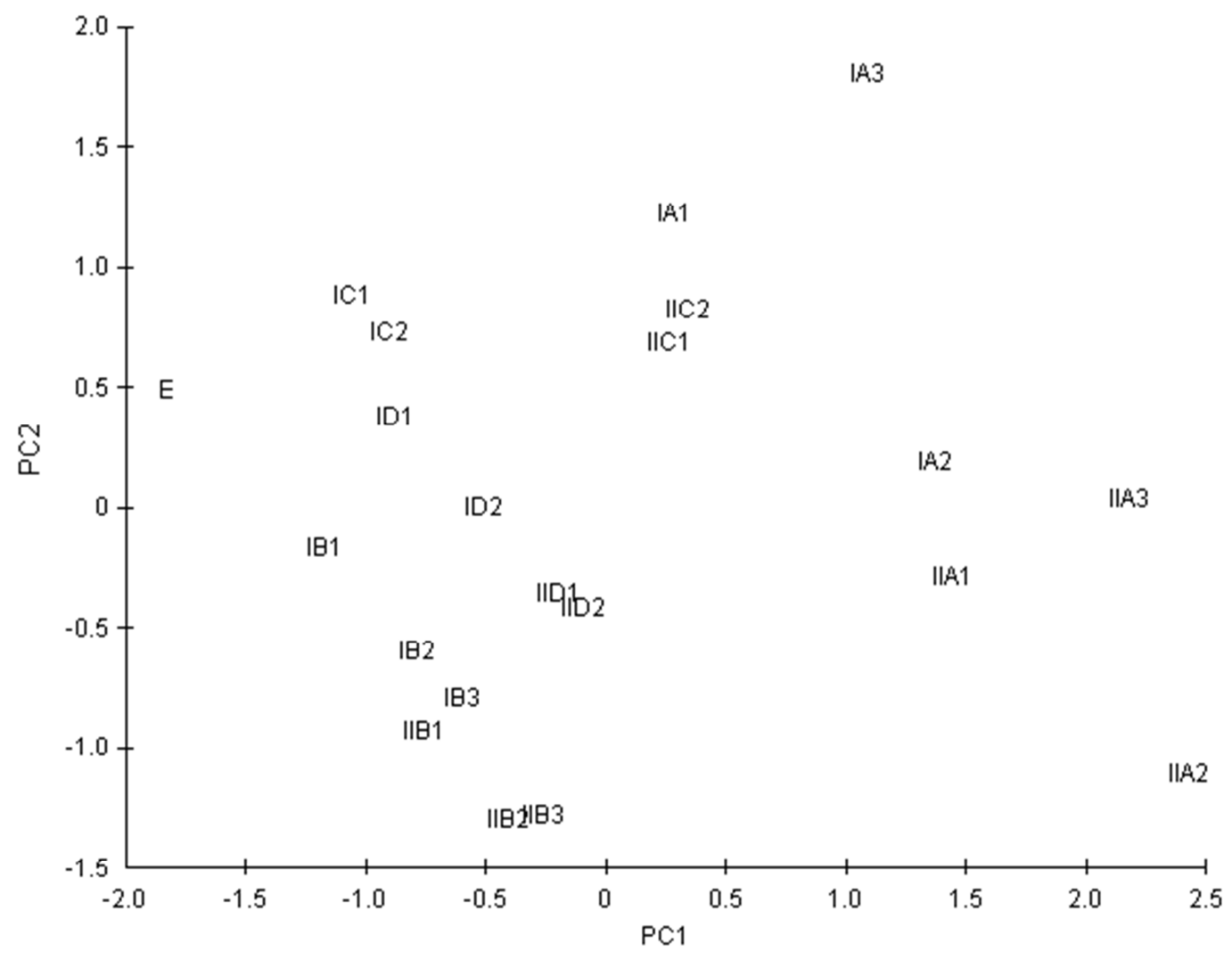

Figure 7. PCA ordination carried out with the two most important environmental variables, salinity and temperature, selected with the BIO-ENV Primer routine. (Axis 1: $63.9 \%$; Axis 2: $36.1 \%$ ). Stations codes as in figure 5 .

\section{Discussion}

The several ordination techniques clearly show an aggregation of stations corresponding with individual water reservoirs that is independent of the time of sampling. Sites $B$ and $E$ stations were separated from site A stations, while sites $C$ and $D$ remained in an intermediate position. However, when higher taxonomic levels were considered, such as large taxonomic groups, instead of families, the separation of stations among sites was not so clear. Stations from sites $B$ and $E$ are all mixed. The same happens with some stations from sites A, C and D. Differentiation of sites when Phyla were considered was even worse.

In previous analysis of the first four sites, where data was organised at the species level (full data set or reduced data set with only the most abundant species), or in 12 biomass categories, the differentiation of stations/sites was consistent whichever data set was used (Gamito, 1997). Apparently there was a degree of redundancy in the data, since a subset of taxa closely reproduced 
the patterns defined by the full data set (cf. Gray et al., 1988). This is probably because site differences were so great that any reasonable group of taxa would show the same pattern of variation. However, this consistency was not observed when large taxonomic groups or Phyla were considered. In an analysis of macrobenthic data, Gray et al. (1988) indicated that no information would be lost if the organisms had been identified to family level only. Warwick (1988), for the same macrobenthic data, pointed out that the multivariate analysis of Phyla results varied, depending on whether abundance or biomass was used and in the strength of data transformation, but generally the agreement between species or family and phyla configurations were good. This author recommended a weak or no data transformation to accentuate the differentiation between sites. In our case the differentiation between sites was even worse when no transformation was performed. It seems that the use of taxonomic resolution higher than the family level is not recommended for the present data set. Karakassis \& Hatziyanni (2000) also concluded that for macrofauna data from sites subjected to a varying degree of disturbance due to sea bream and sea bass farming in the Mediterranean, the best balance between results and taxonomic resolution was obtained at the family level.

The observation of the CCA plot made it possible to detect a strong environmental gradient, related to increasingly stressful conditions due to limited water exchange, with large environmental variations occurring at some sites ( $A$ and $C$, second year). A second gradient with higher values of BOD might be related to increasing eutrophication and a consequent deterioration of water quality. However, this environmental factor, with a small arrow length, is apparently not so important for station differentiation, in contrast to the findings of a previous analysis of data from the first four sites (Gamito, 1997). In that study more environmental variables were included, and the first CCA axis was related, as here, with a gradient of increasing variability of the environmental conditions due to reduced water renewal rates. The organisation of the data matrix in families and not in species apparently did not modify the main results.

The water reservoirs studied here presented some differentiation that can be related to water renewal regimes. Site $A$, where the water was only renewed every fourteen days, can be characterized by large environmental variations between neap and spring tides. The salinity varied from 13 to 84 psu and primary production and macrofauna biomass was always low. The low diversity community was composed of abundant small sized organisms. Migration of juveniles into the reservoir apparently was not a limitation, as the reservoir was open twice a month, but the harsh environmental conditions might have caused low survival rates.

Two reservoirs, sites $B$ and $E$, showed the highest diversity indexes. Here the water was renewed daily and the environmental variation between neap and spring tides was low. However, primary production and macrofauna biomass was higher in site $B$ than in site $E$. In site $E$, the greater depth, along with the naturally high water turbidity of the Ria Formosa, might have prevented macroalgae and seagrass from rooting and developing on the bottom, in contrast to site 
B where the bottom was covered by phanerogams. In fact it is light availability that mainly governs seagrass growth in moderately nutrient enriched regions (Moore \& Wetzel, 2000). The presence of vegetation allows small benthic animals to settle, develop and reproduce, protected from predation. Seagrasses increase the spatial complexity of the community structure by amplifying both surface and volume five fold, when compared with non-vegetated areas. The development of seagrass meadows stimulates the abundance and biomass of the indigenous macrobenthic assemblages, and it also increases diversity and specialisation of feeding gilds (Hily \& Bouteille, 1999).

The other two water reservoirs displayed intermediate characteristics. However, mean BOD concentrations were higher than in the other water reservoirs, along with chlorophyll a concentration, especially in site $\mathrm{C}$ during the second year. In fact, in the beginning of the second year, there was an intense development of phytoplankton at this site.

During that period, the water was green and very turbid, and some dead fish were found. Krom (1989) considered that in 'low flow rate fish ponds the algal populations have the tendency to overshoot and then collapse.

Occasional environmental instability is usual in these water reservoirs where there is an excessive production of organic matter that can be followed, in extreme situations, by total consumption of oxygen during the night and massive mortalities (Krom et al., 1985, 1989; Sorokin et al., 1996; Lardicci et al., 1997). During the neap tides the water quality deteriorated, due to a decrease in the water renewal rate and also due to the lower quality of the incoming water. This deterioration was more pronounced in sites $C$ and D and extreme in site A (Gamito, 1994, 1997).

The macrofauna observed in the five water reservoirs is characteristic of estuarine or shallowwater habitats (Gamito, 1997) and common in the Ria Formosa lagoonal system (Sprung, 1993, 1994). Apparently, when the environmental conditions are more stable, more species can settle and find the appropriate conditions for growth and reproduction. Organisms with larger body size and higher biomasses develop in these sites. The species present in large abundance in the more extreme conditions may remain, but at lower density, mainly due to the lower competitive capacity. The stressful environmental conditions encouraged high-density populations of small sized organisms, such as Capitella capitata, Cerastoderma glaucum, Hydrobia spp. and Chironomius salinarius. These findings agree with those of

Hargrave \& Thiel (1983) and Schwingammer (1981), who found that in the absence of exogenous disturbances, biomass may accumulate in large organisms, while environments characterized by variability or persistent physical stress appear to be dominated by communities of small-sized organisms.

Coastal lagoons offer a protected shallow habitat, which can be highly productive (Alongi, 1998). Well structured communities, controlled by K-strategists, can develop and settle in leaky lagoons, that is, lagoons with wide entrance channels and tidal currents which permit good water renewal. In these lagoons, biomass can accumulate in the form of large organisms, while lagoons with a single 
narrow entrance that can be closed for long periods are characterised by persistent physical stress, and are dominated by communities of small-sized r-strategists organisms (Gamito et al., 2005).

\section{Acknowledgements}

This work was partially supported by a INIC $\mathrm{PhD}$ scholarship and by the project $\mathrm{PBIC/C/MAR/2226/95}$. Special thanks are due to several colleagues and students from the FCMA, University of Algarve, and from IPIMAR (Olhão), who helped in the field and laboratory work and macrofauna identification, and Karim Erzini for English revision of the text. The comments of two anonymous referees greatly improved the manuscript.

\section{References}

Águas, M. P., 1986. Simulação da circulação hidrodinâmica na Ria Formosa. in: Os sistemas lagunares do Algarve. Univ. do Algarve, Faro pp. 78-90 .

Alongi, D. M., 1998. Coastal Ecosystem Processes. CRC Press,Boca Raton. Florida.

CCRA (Comissão de Coordenação da Região do Algarve), 1984. Programa de ordenamento e desenvolvimento da Ria Formosa. Vol. 1 - Caracterização, objectivos e acções, Faro

Falcão, M.M. \& C. Vale, 1990. Study of the Ria Formosa ecosystem: benthic nutrient remineralization and tidal variability of nutrients in the water. Hydrobiologia 207: 137-146.

Gamito, S., 1989. The benthic macrofauna of some water reservoirs of salt-pans from Ria Formosa (Portugal). Scientia Marina 53: 639-644.

Gamito, S., 1994. The benthic ecology of some Ria Formosa lagoons, with reference to the potential for production of the gilthead seabream (Sparus aurata L.). PhD Thesis, UCTRA, University of Algarve. $255 \mathrm{p}$.

Gamito, S., 1997. Application of canonical correspondence analysis to environmental and benthic macrofauna data of four sites in the Ria Formosa (Portugal). Publicaciones Especiales Instituto Español de Oceanografía 23: 41-52.

Gamito, S., A. Pires, C. Pita \& K. Erzini, 2003. Food availability and the feeding ecology of ichthyofauna of a Ria Formosa (South Portugal) water reservoir. Estuaries 26: 938-948.

Gamito, S., J. Gilabert, C. Marcos Diego \& A. Pérez-Ruzafa, 2005. Effects of changing environmental conditions on lagoon ecology. In Gönenc, , I. E. \& J. Wofflin (eds.), Coastal Lagoons: Ecosystem processes and modeling for sustainable use and development, CRC Press, Boca Raton. pp: 193229.

Gray, J.S., M. Aschan, M.R. Carr, K.R. Clarke, R.H. Green, T.H. Pearson, R. Rosenberg \& R.M. Warwick, 1988. Analysis of community attributes of the benthic macrofauna of Frierfjord / Langesundfjord and in a mesocosm experiment. Marine Ecology Progress Series 46: 151-165.

Hargrave, B.T. \& H. Thiel, 1983. Assessment of pollution induced changes in benthic community structure. Marine Pollution Bulletin 14: 41-46.

Hily, C. \& M. Bouteille, 1999. Modifications of the specific diversity and feeding guilds in an intertidal sediment colonized by an eelgrass meadow (Zostera marina) (Brittany, France). Comptes Rendus de L'Academie des Sciences - Sciences de la Vie 322: 1121-1131.

Karakassis, I. \& E. Hatziyanni, 2000. Benthic disturbance due to fish farming analysed under different levels of taxonomic resolution. Marine Ecology Progress Series 203: 247-253.

Kjerfve, B., 1994. Coastal lagoons. In Kjerfve, B. (ed.) Coastal Lagoon processes. Elsevier, Amsterdam: 1-8.

Krom, M.D., C. Porter \& H. Gordin, 1985. Description of the water quality conditions in a semi-intensively cultured marine fish pond in Eilat, Israel. Aquaculture 49: 141-157.

Krom, M.D., A. Neori \& J. van Rijn, 1989. Importance of water flow rate in controlling water quality processes in marine and fresh water fish ponds. The Israelli Journal of Aquaculture 41 23-33.

Lardicci, C., F. Rossi \& A. Castelli, 1997. Analysis of macrozoobenthic community structure after severe dystrofic crises in a Mediterranean coastal lagoon (Orbetello, Italy). Marine Pollution Bulletin 34: 536547. 
Moore, K. A. \& R.L. Wetzel, 2000. Seasonal variations in eelgrass (Zostera marina L.) responses to nutrient enrichment and reduced light availability in experimental ecosystems. Journal of Experimental Marine Biology and Ecology 244: 1-28.

Olsgard, F., P. J. Somerfied \& M. R. Carr, 1998. Relationships between taxonomic resolution, macrobenthic community patterns and disturbance. Marine Ecology Progress Series 172: 25-36.

Pilkey, O.H., W.J. Neal, J.H. Monteiro \& J.M.A. Dias, 1989. Algarve barrier islands: a noncoastal-plain system in Portugal. Journal of Coastal Research 5: 239-261.

Rumohr, H. \& I. Karakassis, 1999. Comparison of multivariate patterns: different taxonomic levels in macrofaunal analysis versus sediment profiling imagery (SPI). Marine Ecology Progress Series 190: 125-132.

Schwinghamer, P., 1981. Characteristic size distribution of integral benthic communities. Canadian Journal of Fisheries and Aquatic Sciences 38: 1255-1263.

Sorokin, Y.I., P.Y. Sorokin \& A. Gnes, 1996. Structure and functioning of the anthropogenically transformed Commacchio lagoonal ecosystem (Ferrara, Italy). Marine Ecology Progress Series 133: 57-71.

Sprung, M., 1993. Estimating macrobenthic secondary production from body weight and biomass: a field test in a nonboreal intertidal habitat. Marine Ecology Progress Series 100: 103-109.

Sprung, M., 1994. Macrobenthic secondary production in the intertidal zone of the Ria Formosa - a lagoon in Southern Portugal. Estuarine Coastal and Shelf Science 38: 539-558.

Warwick, R.M., 1988. Analysis of community attributes of the macrobenthos of Frierfjord/Langesundfjord at taxonomic levels higher than species. Marine Ecology Progress Series 46: 167-170.

Warwick, R.M., H.M. Platt, K.R. Clarke, J. Agard \& J. Gobin, 1990. Analysis of macrobenthic and meiobenthic community structure in relation to pollution and disturbance in Hamilton Harbour, Bermuda. Journal of Experimental Marine Biology Ecology 138: 119-142. 